\title{
Francisco y los movimientos populares: un encuentro para pensar el cambio social"
}

\author{
John Carlos Pumacaya Carbajal ${ }^{* *}$
}

Recepción: 4 de febrero de 2018 • Aprobación: 12 de marzo de 2018

\section{Resumen}

La corazonada social en torno a la elección de un papa latinoamericano, Francisco, se ha ido materializando no solo en las comunicaciones tradicionales de un pontífice, sino también en el encuentro con hombres y mujeres de distintos lugares y creencias cuyo punto común es la lucha social por otro mundo. Este encuentro traza una ruta eclesial y epistémica que implica la revisión crítica de los principios vitales del cristianismo y de los marcos analíticos de la realidad social. El artículo se inscribe en la perspectiva de iniciar un diálogo con las fuerzas populares que buscan defender la vida.

Palabras clave: movimientos populares, comunidad, Francisco, pobre; encuentro.

Artículo de reflexión resultante de la ampliación de la ponencia presentada para el Congreso de Teología en la Pontificia Universidad Javeriana en octubre de 2017. Citar como: Pumacaya Carbajal, J. (2018). Francisco y los movimientos populares: un encuentro para pensar el cambio social. Revista Albertus Magnus, IX(1), 133-150. Doi: https://doi.org/10.15332/s20119771.2018.0001.06

** Pontificia Universidad Javeriana. Bogotá, Colombia. Correo electrónico: jpumacaya@ javeriana.edu.co 


\title{
Francis and the popular movements: A meeting to think about social change
}

\begin{abstract}
The social hunch around the election of a Latin American Pope, Francisco, has been materialized not only in the traditional communications of a pontiff but fundamentally in the encounter with men and women of different places and beliefs whose common point is the social struggle for another world. This meeting traces an ecclesial and epistemic route that implies the critical revision of the vital principles of Christianity and the analytical frameworks of social reality. The text is part of the perspective of initiating a dialogue with the popular forces that seek to defend life.
\end{abstract}

Keywords: popular movement, comuntiy, Francis, poor, meeting.

\section{Francisco e os movimentos populares: um encontro para pensar em mudança social}

\section{Resumo}

O pressentimento social em torno da eleição de um papa latino-americano, Francisco, se materializou não apenas nas comunicações tradicionais de um pontífice, mas fundamentalmente no encontro com homens e mulheres de diferentes lugares e crenças cujo ponto comum é a luta social para outro mundo. Este encontro traça um caminho eclesial e epistêmico que implica a revisão crítica dos princípios vitais do cristianismo e os elementos analíticos da realidade social. A perspectiva do texto é um diálogo com as forças populares que buscam defender a vida.

Palavras-chave: movimento popular, comunidade, Francisco, pobre; encontró.

\section{Introducción}

La elección del cardenal Bergoglio como papa fue una gran sorpresa. Por primera vez se tenía un papa latinoamericano, buscado en "el fin del mundo", como él mismo mencionó en su primera intervención. No faltó quienes corearon que tal elección significaría darle el rostro latinoamericano a la Iglesia. Se avizoraba, pues, una agenda temática de profunda sensibilidad por los problemas sociales 
del mundo contemporáneo, en la que la cuestión de los pobres, aunque no estaba ausente en los magisterios precedentes, sería el alma de una acción papal, delineada por la elección del nombre, Francisco, caracterizada por gestos y discursos con un estilo que ha encendido más de un corazón.

En estas líneas, se va a señalar cómo esa sensibilidad se ha traducido en el encuentro de Francisco con los movimientos populares. Por primera vez un papa se relaciona con las bases de resistencia, lo cual no pocas veces genera simpatía y vigilancia en muchos sectores sociales y académicos. El artículo comienza postulando que, antes del encuentro con los movimientos populares, Francisco aún respiraba aquella tradición teológica que había hecho del pobre un objeto de cuidado, inclusión y liberación. Enseguida, se pretende desarrollar por el talante de sus comunicaciones a los movimientos populares (Roma, 2014; Santa Cruz de la Sierra, 2015; Roma, 2016) un giro en la comprensión del pobre. Este deja de ser visto como objeto para ser sujeto, agente de la transformación social. Posteriormente, se realiza una aproximación más detenida al mundo de los movimientos populares. Auxiliado por las ciencias sociales, se busca trazar su genealogía y su fundamento comunitario para el cambio social. Finalmente, resulta imperiosa una lectura teológica, es decir, identificar el punto de encuentro y diálogo de los movimientos populares con la tradición cristiana, en especial aquella que se ha desarrollado en América Latina desde la praxis y el pensamiento liberador.

\section{Evangelii gaudium y el pobre}

Para comprender la concepción del pobre en la exhortación apostólica, es necesario conectarla con la XIII Asamblea General Ordinaria del Sínodo de los Obispos, que se llevó a cabo del 7 al 28 de octubre de 2012 en Roma. Este sínodo, inaugurado por Benedicto XVI, reflexionó sobre la nueva evangelización para la transmisión de la fe. En su mensaje final, además de exhortar un nuevo encuentro con Jesucristo, poniendo a la Iglesia como espacio para ello, y subrayar que el magisterio fundamental del concilio se expresa en el Catecismo de la Iglesia católica, los obispos manifiestan una visión del pobre así:

El otro signo de autenticidad de la nueva evangelización tiene el rostro del pobre. Situarse junto a quien está herido por la vida no es solo ejercicio de socialidad, sino ante todo un hecho espiritual [...] A los pobres les reconocemos un lugar privilegiado en nuestras comunidades, un puesto que no excluye a nadie, pero que quiere ser un reflejo de cómo Jesús se ha unido a ellos. La presencia [las cursivas son mías] del pobre en 
nuestras comunidades es misteriosamente potente: cambia a las personas más que un discurso, enseña fidelidad, hace entender la fragilidad de la vida, exige oración; en definitiva, conduce a Cristo. (XIII Asamblea general, 2012)

Esta concepción sinodal no soslaya al pobre, sino que su existencia es un hecho. Pero ¿cuál es la visión del pobre en la nueva evangelización? Inicialmente, se puede indicar que se trata de un sujeto cuya vida es importante para la Iglesia. Sin embargo, el texto resulta muy general. Al igual que en los Lineamenta del Sínodo, el pobre es una realidad marginal. Evangelii gaudium se une al mensaje sinodal cuando sostiene que "cada cristiano y cada comunidad están llamados a ser instrumentos de Dios para la liberación y promoción de los pobres, de manera que puedan integrarse plenamente en la sociedad; esto supone que seamos dóciles y atentos para [las cursivas son mías] escuchar el clamor del pobre y socorrerlo" (EG 187). El para revela lo que palpita en el texto sinodal. Se trata de una construcción dualista: la Iglesia y los pobres. En el caso de la Iglesia, se trata de un sujeto que, fundada en un Cristo que se une a los pobres, está en la obligación de escucharlos y socorrerlos, y en los pobres lo que se encuentra es un sujeto vuelto objeto, es decir, objeto de cuidado y atención eclesial.

El núcleo de esta perspectiva se desarrolla en la exhortación por medio de un rosario de expresiones: "La evangelización dirigida gratuitamente a ellos [pobres]" en el n. 48, "los ricos deben ayudar a los pobres, respetarlos, promocionarlos" en el n. 58, "la falta de acompañamiento pastoral $a$ los más pobres" en el n. 70, "la Iglesia en movimiento de salida de sí [...] de entrega a los pobres" en el n. 97 y "la inclusión social de los pobres" en el n. 185. Pero la expresión que sintetiza esta tendencia reflexiva es: “Quiero una Iglesia pobre para [las cursivas son mías] los pobres" en el n. 198. El para constituye la frontera divisoria que permite erigir a la Iglesia como sujeto institucional que vela por la vida del pobre.

Autores como Juan Carlos Scannone y Walter Kasper, reflexionando sobre el magisterio de Francisco, han indicado que el papa se ubica en la teología del pueblo. Para el jesuita argentino, "el tema de los pobres es un punto de convergencia entre el magisterio del papa Francisco, la doctrina social de la Iglesia y la Teología del pueblo" (Scannone, 2015, p. 50). Por su parte, el cardenal alemán sostiene que Francisco desarrolla una eclesiología del Pueblo de Dios a partir de la teología del pueblo (Kasper, 2015, pp. 61-73), lo cual no debe confundirse con el peronismo, ya que sus raíces son europeas (pp. 34-35). Kasper concluye que "con su pontificado [de Francisco] hemos entrado en una nueva fase [las cursivas son mías] del posconcilio y de la recepción conciliar" (p. 38). 
Esta nueva fase brinda elementos para dibujar la eclesiología latente. Hay una Iglesia constituida que, siendo fiel a sus fundamentos evangélicos, va al encuentro de los pobres. Ella tiene el deber de promocionar a los más débiles de la historia. Esta opción preferencial por el pobre, que ya está embrionariamente en el Sínodo de obispos, comprende una teología eclesial en la que ve al pobre como objeto del cuidado eclesial, de liberación e inclusión social. La Iglesia se une al pobre, le reconoce un lugar especial, pero no se ve interpelada en sus fundamentos.

Se ha visto que esta eclesiología latente tiene sus raíces en el Sínodo de 2012. Sin embargo, hay algo más de fondo que la Iglesia latinoamericana no ha resuelto, a saber: el dualismo Iglesia/pobres. Esta concepción dualista ha sido la razón epistémica que ha respondido a la teología de la liberación que subrayó la deconstrucción de la Iglesia desde los pobres. El retorno del dualismo como razón epistémica ha frenado los procesos de reinvención teológica y eclesial en un continente explotado. El dualismo como contrainsurgencia conceptual, no solo revela la matriz metafísica de la fe, sino la aseveración de un statu quo eclesial.

Un ejemplo para ilustrar las líneas anteriores es el famoso artículo de Clodovis Boff titulado "Teología de la liberación y vuelta al fundamento", de 2007. El texto desarrolla una perspectiva dualista: Cristo y el pobre. Pero lo significativo es que esta operación epistémica la conecta con Aparecida, es decir, el asunto de Clodovis responde a la conciencia teológica de un sector importante de Iglesia a la hora de comprenderse en un continente pobre. Carlos Angarita revela el núcleo de esta operación epistémica:

El examen de su escrito evidencia que su reflexión se mueve permanentemente en el orden de la lógica y de los principios: Cristo y el pobre - centro de su controversia-, y sus respectivas correlaciones, son presentados como tales. Si bien en el plano de la teología son susceptibles en determinado momento de abstraerse a manera de categorías, no obstante, para ser congruente con una teología histórica se necesita el desarrollo de un método que garantice los vínculos con la experiencia. Esta, la experiencia, no parece preocuparle a Clodovis, sino solo en tanto objeto de los juicios de valor que profiere desde los principios de fe que previamente ha establecido. Incluso justifica o hasta celebra (en favor de la defensa de un supuesto "Cristo vivo") que en el documento de Aparecida se coloque en un lugar secundario la mención y el análisis de la crisis de nuestro tiempo, es decir, la comprensión de las actuales circunstancias históricas donde se despliega la fe cristiana. (Angarita, 2016, pp. 142-143) 
En efecto, se trata de la relativización, o peor aún, de la prescindencia de la experiencia. Las líneas de Evangelii gaudium a propósito del pobre hacen parte de aquella tradición teológica que respondió a las experiencias fundantes de las cuales había nacido la teología de la liberación. Concebir apriorísticamente el carácter constituido de la Iglesia es levantar muros conceptuales e institucionales que no permiten el encuentro experiencial con los hombres y con las mujeres que hacen la historia. En este sentido, Francisco no haría más que desarrollar tal perspectiva con un dejo latinoamericano. La opción preferencial por el pobre no pasaría de un paternalismo eclesial. Por tal razón, la vinculación de Francisco con la teología de la liberación es inexistente desde el punto de vista del reconocimiento del pobre como sujeto.

Sin embargo, Francisco por medio de la cultura del encuentro se ha ido alejando de esa visión objetual del pobre. Los encuentros con los movimientos populares revelan un cambio epistémico. En sus pronunciamientos, el papa reconoce el papel transformador de los pobres. Al escuchar los problemas, los temores y las alegrías de aquellos, es imposible no dejarse interpelar por sus rostros y callos de lucha. En otras palabras, la vuelta a la experiencia sufriente permite redibujar las fronteras de las categorías y repensar las imágenes del mundo social.

\section{Los encuentros con los movimientos populares}

João Pedro Stédile, miembro del Movimento dos Trabalhadores Rurais Sem Terra (MST) y de la Vía Campesina de Brasil, cuenta que desde el segundo semestre de 2013 el papa quería establecer un diálogo con los movimientos populares. A finales de ese mismo año, se realizó un seminario a propósito de las desigualdades sociales en el mundo y cómo los movimientos ven esos problemas. En ese seminario, se le entregó a Francisco un documento de por qué las semillas transgénicas y los agrotóxicos son un peligro para la naturaleza y la humanidad. Después de este encuentro previo, Francisco convocó un encuentro en octubre de 2014 en Roma. El militante brasileño comenta con emoción ese acercamiento por parte del papa latinoamericano:

Nos encontramos más de 180 representantes de movimientos de trabajadores de todo el mundo, con una amplia pluralidad de credos religiosos, etnias, género, juventud, orientación sexual y representación geográfica, de todos los continentes. No hubo de parte del papa Francisco o del Vaticano ningún condicionamiento [las cursivas son mías]. El encuentro fue histórico. Por primera vez en la historia del Vaticano, el papa se 
encontró con representantes de movimientos populares. Nos reunimos en el salón del Sínodo viejo, utilizado por siglos solamente por cardenales. Él mismo reveló que nunca antes había estado en ese lugar. Y ahí analizamos los problemas que enfrentan los trabajadores/as, sus causas y las propuestas para encontrar salidas. (Stedile, 2015, p. 2)

El Vaticano ha sido el territorio institucional de la Iglesia católica para reunirse con los jefes de Estado y los altos diplomáticos. Francisco, al recibir a los movimientos populares en ese territorio, muestra su actitud de escuchar a otras voces sociales que a menudo no son tenidas en cuenta por los líderes políticos. El Vaticano hospedó la resistencia popular. Con este acercamiento directo a los movimientos populares, Bergoglio comienza a distanciarse de la visión objetual del pobre. Sin formalismos lingüísticos, Francisco reconoce el carácter protagonista de los pobres:

¡Los pobres no solo padecen la injusticia sino que también luchan contra ella! No se contentan con promesas ilusorias, excusas o coartadas. Tampoco están esperando de brazos cruzados la ayuda de ONGs [sic], planes asistenciales o soluciones que nunca llegan o, si llegan, llegan de tal manera que van en una dirección o de anestesiar o de domesticar. Esto es medio peligroso. Ustedes sienten que los pobres ya no esperan y quieren ser protagonistas, se organizan, estudian, trabajan, reclaman y, sobre todo, practican [las cursivas son mías] esa solidaridad tan especial que existe entre los que sufren, entre los pobres, y que nuestra civilización parece haber olvidado, o al menos tiene muchas ganas de olvidar. (Francisco, 2016a)

El obispo de Roma reconoce que la acción de los movimientos populares es "un modo de hacer historia" con "olor a barrio, a pueblo, a lucha". Para él, son ellos los que luchan por las tres T: Tierra, Techo, Trabajo, los cuales son derechos sagrados. El papa les dice a los movimientos que la lucha de ellos pertenece a la Doctrina Social de la Iglesia. Y denunciando sin pelos en la lengua que la persona no está en el centro del sistema idolátrico de la economía, Francisco termina animando a los movimientos populares que sigan en esa lucha.

Esta cultura del encuentro continuó en Santa Cruz de la Sierra en julio de 2015. El papa fue muy incisivo en la necesidad de un cambio redentor frente a la economía que mata. Y reafirmó el papel de los pobres con más radicalidad:

Ustedes, los más humildes, los explotados, los pobres y excluidos, pueden y hacen mucho. Me atrevo a decirles que el futuro de la humanidad está, 
en gran medida, en sus manos, en su capacidad de organizarse y promover alternativas creativas, en la búsqueda cotidiana de "las tres $T$ " [las cursivas son mías] [...] y también, en su participación protagónica en los grandes procesos de cambio. Cambios nacionales, cambios regionales y cambios mundiales. ¡No se achiquen! (Francisco, 2016b)

Lo plausible de este segundo encuentro es la afirmación de que el futuro de la humanidad está en gran medida en las manos de los movimientos. Reconoce en la lucha popular la esperanza para otro mundo. A esto se suman expresiones como sembradores del cambio, los pueblos del mundo quieren ser artífices de su propio destino y poetas sociales, que complementan la valoración que Francisco hace de los movimientos. Siendo consecuente con aquello que significa la resistencia popular, llama a la Iglesia para que siga profundizando en este diálogo.

En noviembre de 2016 en Roma, Francisco una vez más se encontró con los movimientos populares. Nuevamente, se ratificó el compromiso con las tres T. En esta ocasión, lleva a lejos la reflexión sobre los pobres. Reconoce el contenido de su acción:

A veces pienso que cuando ustedes, los pobres organizados, se inventan su propio trabajo, creando una cooperativa, recuperando una fábrica quebrada, reciclando el descarte de la sociedad de consumo, enfrentando las inclemencias del tiempo para vender en una plaza, reclamando una parcela de tierra para cultivar y alimentar a los hambrientos, cuando hacen esto están imitando a Jesús [las cursivas son mías] porque buscan sanar, aunque sea un poquito, aunque sea precariamente, esa atrofia del sistema socioeconómico imperante que es el desempleo. No me extraña que a ustedes también a veces los vigilen o los persigan y tampoco me extraña que a los soberbios no les interese lo que ustedes digan. (Francisco, 2016b)

Él no solo reconoce el protagonismo de los pobres, sino que se aproxima a lo que hacen. Nombra la acción cotidiana de los pobres. El juicio del papa proviene no de la especulación, sino del conocimiento de la acción de ellos. Al acercarse a la realidad popular, la conmoción es inevitable; interpela las certidumbres y cuestiona las formas de concebir la realidad.

El pronunciamiento revela una conexión que supera la mera descripción. Se trata de la identificación de la acción popular con la acción de Jesús. El verbo que se utiliza es imitar. Se trata de una categoría que ha sido fundamental dentro de la espiritualidad cristiana. El término comprendía la ascesis de la vida interior. 
Aunque no haya una precisión de la categoría, su sentido en el texto revela una conexión teológica. La imitación de Jesús pasa por la acción popular. En otras palabras, la espiritualidad también se comprende como una postura crítica y transformadora de los sistemas que oprimen a los seres humanos y a la naturaleza. Imitar a Jesús es desarrollar una ascesis social en favor de la vida.

Ahora bien, la reflexión sobre los pobres no se detiene. El papa se aproxima a la autonomía. Los movimientos populares han sufrido la cooptación de los Estados por medio de las políticas sociales. Con ello se ha buscado domesticar la lucha popular. La consecuencia es la diminución de la autonomía. Escuchando ese clamor, Francisco se une a la conciencia popular de enfrentar los mecanismos de neutralización institucional:

Esa idea de las políticas sociales concebidas como una política hacia los pobres pero nunca con los pobres, nunca de [las cursivas son mías] los pobres y mucho menos inserta en un proyecto que reunifique a los pueblos a veces me parece una especie de volquete maquillado para contener el descarte del sistema. Cuando ustedes, desde su arraigo a lo cercano, desde su realidad cotidiana, desde el barrio, desde el paraje, desde la organización del trabajo comunitario, desde las relaciones persona a persona, se atreven a cuestionar las "macro-relaciones", cuando chillan, cuando gritan, cuando pretenden señalarle al poder un planteo más integral, ahí ya no se lo tolera. No se lo tolera tanto porque se están saliendo del corsé, se están metiendo en el terreno de las grandes decisiones que algunos pretenden monopolizar en pequeñas castas. (Francisco, 2016a)

La autonomía no solo comprende aprender a blindarse de la cooptación, sino que también incorpora una actitud crítica al sistema. En Bolivia, Francisco había dicho que este "sistema ya no se aguanta". Pero en esta ocasión la crítica es contundente. Refiriéndose al gobierno del dinero, afirma que "ese sistema es terrorista [las cursivas son mías]". El terrorismo es una noción que se ha aplicado al enemigo inventado a razón de su insurgencia o disidencia al orden establecido. Francisco no lo utiliza en ese sentido. Lo lleva a nivel estructural, puesto que las estructuras económicas y políticas que determinan la vida contemporánea generan inequidad y muerte. Por ello, no duda en calificar de terrorista el sistema. Si bien es cierto que él no hace mención del capitalismo como estructura económica, no es menos cierto que su afirmación se mueve en el terreno de la crítica sistémica al capital. Terrorista no es el potencial enemigo al que hay que erradicar, sino aquel que pone en el centro al ídolo dinero en vez del ser humano y la naturaleza. 
Este encuentro con los movimientos populares no es solo un diálogo entre el pontífice y los pobres. Ha comenzado a convertirse en una politica eclesial, sobre todo en América Latina. Del 12 al 16 de septiembre de 2017 en Perú, las pastorales Cáritas de América Latina y el Caribe con los movimientos sociales, el Departamento de Justicia y Solidaridad (Dejusol) del Consejo Episcopal Latinoamericano (Celam) organizaron un encuentro continental con la siguiente denominación: Diálogo entre la Iglesia Latinoamericana y los Movimientos Populares. Con la metodología ver, juzgar y actuar, el encuentro diseñó temáticas que ayudaron a profundizar en la lucha social de los movimientos populares. Este hito histórico ha traído como consecuencia una carta a los gobernantes y a los pueblos de América Latina y el Caribe en que se exponen las críticas fundamentales al modelo de sociedad que viene dándose desde la Colonia.

Pues bien, este recorrido papal, perfilándose en política eclesial, proporciona elementos para afirmar la distancia epistémica a propósito del pobre. La concepción objetual del pobre, de la que hace parte la exhortación apostólica EG y la tradición teológica que respondió a la subversión epistémica de la teología de la liberación, comienza a desvanecerse debido al encuentro con la lucha popular. No se trata de un problema temático, sino de la existencia social. Dejarse interpelar por la fuerza de los que luchan por otro modelo de sociedad y economía no es otra cosa que la apertura para deconstruir el mundo categorial y las prácticas de transformación. Atrás queda el paternalismo eclesial a los pobres. En adelante, el pobre es un interlocutor en el cambio que se necesita. En vocabulario cristiano, se trata de repensar, por medio del contacto con el otro sufriente, los caminos de existencia social para vivir la fe.

\section{3. ¿Por qué escuchar y mirar a los movimientos populares?}

Desde el encuentro y el magisterio, Francisco ha visibilizado la lucha popular que hoy recorre nuevos senderos. Se ha visto que las iglesias, en especial la latinoamericana, han abrazado esa iniciativa papal. Pero no basta con quedarse en una lectura pontifical del asunto, ni tampoco equiparar de manera genérica pobres con movimientos populares. Es menester hacer una aproximación más precisa de lo que está en juego en los movimientos populares, es decir, de aquello que constituye su fundamento para el cambio social.

Raúl Zibechi, pensador y militante uruguayo, identificó inicialmente que los movimientos populares en América Latina tienen sus raíces en "las comunidades 
eclesiales de base vinculadas a la teología de la liberación, la insurgencia indígena portadora de una cosmovisión distinta de la occidental y el guevarismo inspirador de la militancia revolucionaria" (2003, pp. 185-188). Estas palabras en los inicios del siglo daban luces para comprender el porqué de la lucha y el grito de los movimientos populares. El cristianismo de liberación, la resistencia indígena y la militancia revolucionaria constituyeron el tridente latinoamericano para defenderse de las acciones de recolonización. Sin embargo, con el paso de los años y con un mayor contacto con la realidad, el pensador austral ha reconocido dos raíces más en esa genealogía, a saber: el papel de la educación popular y el protagonismo de las mujeres y de los feminismos. Las cinco raíces tuvieron como eje común la praxis emancipadora, lo que dio lugar a una tradición liberadora.

Los movimientos populares son hijos de esa tradición, de ese despertar social que ha estado presente en América Latina para frenar los embates de la opresión. Hoy, con nuevas configuraciones, esos movimientos siguen las huellas del ayer desarrollando una lucha particular. Una herencia incuestionable es la construcción de la comunidad, ya que a partir de ella se transforma el mundo.

La vieja cultura política comprendía la revolución como toma del poder. Ya sea por vía legal (partido político), ya sea por vía ilegal (movimientos guerrilleros), el imaginario dominante estimaba que la transformación social solo sería posible por medio del control estatal. La razón epistémica de la revolución fue la existencia y la localización del poder. Según Holloway, "una vez que se adopta la lógica del poder, la lucha contra el poder ya está perdida" (2002, p. 33). Los movimientos populares han tomado conciencia de esta experiencia. La institucionalización estatal de la fuerza popular desplaza la lucha social al ámbito de los consensos y de las formalidades. No obstante, es necesario advertir que el paradigma de la revolución como toma del poder, importado acríticamente del mundo occidental, ha mostrado sus fisuras, fundamentalmente, por la aparición de nuevas formas de organización social. La ruptura con la vieja cultura política ha sido posible por el redescubrimiento de la comunidad como fundamento de una nueva vida social.

Zibechi afirma que "la comunidad no es, se hace; no es una institución, ni siquiera una organización, sino una forma que adoptan los vínculos entre las personas" (p. 48). La levadura de esos vínculos es la esperanza por otro mundo posible. El nervio de la convocación comunitaria no es la conformación de un club de hinchas o fans, sino el cambio social en favor de la vida mediante nuevas relaciones sociales, para lo cual es necesario que las personas tomen conciencia de su vida cotidiana. Cuando se inicia un camino de transformación en las relaciones sociales, la comunidad se vuelve la respuesta efectiva al mundo hegemónico del capital que niega al ser humano y la naturaleza. 
Los verbos fundamentales de la comunidad son resistir y crear. Resistir la embestida de los poderes estatales que mediante sus políticas sociales cooptan la autonomía de los pueblos. Resistir la fuerza pública que se utiliza para disciplinar y reprimir el descontento social. Resistir el avasallamiento del extractivismo, es decir, el mecanismo económico y político que crucifica a la tierra y a los hombres y mujeres que conviven con ella. En definitiva, resistir el fin de la historia social. La comunidad no es un concepto preexistente, sino un modo insurgente de frenar el látigo de la civilización del capital.

Para resistir hay que crear. En efecto, la creación de economías solidarias, de educación y de pedagogías liberadoras, de administraciones democráticas del poder, de relaciones equitativas en cuanto al género y de investigaciones en medicina alternativa son algunas características del tejido comunitario. Crear el otro mundo a partir de la comunidad, es decir, a partir de la recreación emancipadora de las relaciones sociales:

La comunidad es la forma política que asumen los pueblos para resistir y, al hacerlo, cambian el mundo al cambiar el lugar que ellas ocupan en él [las cursivas son mías]. Las comunidades no preexisten como prácticas colectivas, son producto de la lucha y la resistencia. En el proceso de resistir, de ponerse de pie como sujetos colectivos, los pueblos crean/re-recrean formas de relacionarse que llamamos comunidades. (Zibechi, 2017, p. 79)

Alfonso Torres se une al análisis de los movimientos sosteniendo que su identidad se rehace de acuerdo con los conflictos que ellos tienen que enfrentar:

La identidad colectiva es una construcción que va generando el movimiento, en la medida en que sus actores reconstruyen o elaboran valores, representaciones y narrativas que configuran un sentido de pertenencia, un "nosotros" que los diferencia de un "los otros"; por ello, la identidad de los movimientos se va rehaciendo permanentemente en conflicto con las representaciones y prácticas que sobre estos ejercen el poder y los adversarios. (Torres, 2016, p. 51)

Siguiendo el hilo reflexivo de las líneas anteriores, el criterio epistémico de la sociedad son las prácticas y los pensamientos emancipadores que reproducen la vida. La sociedad es conocida, no por una explicación metafísico-institucional, sino por las dinámicas organizativas de compadrazgo, de amistad, de barrio, de ollas comunitarias, de fiestas, etc., que buscan autonomía de vida social. Zibechi, reflexionando la experiencia del levantamiento de El Alto en Bolivia, indica los genes sociales que producen los movimientos:

\section{Universidad Santo Tomás, Facultad de Teología}


Durante los momentos insurreccionales la movilización disuelve las instituciones, tanto las estatales como las de los movimientos sociales. Las sociedades en movimiento, articuladas desde el interior de su cotidianeidad, fisuran los mecanismos de dominación, rasgan los tejidos del control social, dispersan las instituciones; dejan, en resumidas cuentas, expuestas las fracturas societales que la misma sociedad, al moverse, al deslizarse de su lugar anterior, pone al descubierto. Los tiempos de desbordes, de intensa creatividad colectiva - durante los cuales los grupos sociales liberan gigantescas energías - actúan como relámpagos capaces de iluminar las sociabilidades subterráneas, moleculares, sumergidas, ocultas por el velo de las inercias cotidianas en las que se imponen los tiempos y los espacios de dominación y la subordinación. (2007, p. 43)

Con este acercamiento, las categorías que se habían utilizado para nombrar ese fenómeno social comienzan a tambalear. "Movimiento social o popular" no hace justicia a las características que se ha mencionado debido a que el sintagma se asocia comúnmente con la movilización, de modo que la dimensión comunitaria quedaría eclipsada. La movilización tiene la connotación de protesta de personas con pancartas, picos, banderas, instrumentos musicales, danzas, etc. Sin duda, es una expresión de la lucha social en América Latina. Pero la caracterización de los movimientos va más allá de ello. Los movimientos populares se movilizan siendo y construyendo comunidades. El motor de esos movimientos es la respuesta comunitaria al orden establecido.

Lo mismo hay que decirse de pobres. Indiscutiblemente se trata de una noción que hizo parte de la tradición liberadora que se mencionó líneas arriba. Pero a menudo es confundida con lo económico, dando lugar a una confusión de quiénes serían hoy pobres. Esto no significa desconocer el esfuerzo ingente que los teólogos de la liberación hicieron para darle un vasto contenido a la noción. Lo que se quiere subrayar es que la lucha social de los movimientos populares agrieta el término pobres. Se exige otra categoría para analizar la realidad de esos hombres y mujeres que fueron identificados como pobres.

Por lo anterior, y siguiendo la observación aguda de Zibechi, es más justo hablar de sociedades en movimiento. Lo que se moviliza no es simplemente una protesta o una clase social, sino otro modo de existencia social. La comunidad es su rostro. La comunidad es la llave maestra para entrar en otro mundo posible. A diferencia de los movimientos sindicales, obreros o de partido que se mueven en el paradigma del poder, las sociedades en movimiento buscan construir otro 
mundo desde un arraigo territorial con nuevas relaciones sociales. Dice un miembro del movimiento zapatista: "No nos preocupa el enemigo, nos preocupa cómo vamos a definir una nueva relación entre compañeros [las cursivas son mías]" (2000, p. 103). Es comprender que en las favelas, en el asentamiento humano, en la villa, en los caracoles, en los quilombos, etc., se tejen las sociedades del futuro.

\section{Interpelaciones comunitarias al cristianismo}

Esta brújula social que Francisco indica al encontrarse con estas sociedades en movimiento abre el siguiente interrogante: ¿cómo leer teológicamente estas irrupciones comunitarias cargadas de sudor, de manos encallecidas, de lágrimas, de vida y de muerte, de fracasos y de aciertos? Esta pregunta no es una conclusión lógica del desarrollo textual, sino pausa meditabunda ante una corriente de resistencia vital.

Las sociedades en movimiento son las memorias ambulantes de una tradición comunitaria que marcó la vida de Latinoamérica, a saber, las comunidades eclesiales de base (CEB). Estas, con sus canciones, iconografías, modos populares de leer la Biblia, relaciones horizontales, trazaron un proyecto socioeclesial, a saber: la Iglesia de los pobres. La irrupción comunitaria de tales comunidades intimó a los teólogos latinoamericanos a pensar de manera crítica la Iglesia. Gustavo Gutiérrez recoge, de forma lapidaria, aquella realidad que iba germinando en este continente:

La Iglesia durante mucho tiempo ha sido construida desde dentro, en función del cristianismo y de su extensión y conservación en el mundo, es lo que nos dio el llamado eclesiocentrismo. Una perspectiva más reciente ha llevado a pensar a la Iglesia desde fuera, desde el mundo, un mundo no creyente, frecuentemente hostil; en ese mundo la Iglesia debía ser signo de salvación, afirmaba el Vaticano II. Hoy comprendemos mejor que estamos llamados a construir la Iglesia desde abajo, desde el pobre, desde las clases explotadas, las razas marginadas, las culturas despreciadas. (1979, pp. 37-38)

Este llamado a construir la Iglesia desde abajo indudablemente no se limitaba a una reforma puramente religiosa. A menudo los trabajos eclesiológicos pasan por alto ese criterio. La noción Iglesia de los pobres o popular no es otra categoría de una esfera independiente, sino la apuesta por otro modo de existencia social, de cuño creyente, en el seno de un mundo opresor. Nuevamente las palabras de Gutiérrez 
iluminan con mucha hondura que el grito del cristianismo popular fue grito contra una civilización:

Los pobres, los condenados de la tierra, no cuestionan en primer lugar el mundo religioso, ni sus presupuestos filosóficos. Se trata más bien de un cuestionamiento del orden económico, social, político que los oprime y margina y también por cierto, de la ideología que pretende justificar esa dominación. Solo en ese cuadro se comprenden los desafíos a la fe que vienen desde el mundo de los explotados. $(1979, \text { p. } 350)^{3}$

Esta conexión establecida, no solo permite vincular las sociedades en movimiento con las CEB desde la lucha por otro modo de existencia social, sino que permite cuestionar el concepto de Iglesia.

Al igual que otras categorías teológicas, Iglesia no pocas veces se presenta como una noción envejecida y mancillada por los problemas que se le atribuyen de acuerdo con su historia institucional. Los teólogos intentan mantenerla viva con ejercicios deconstructivos buscando recuperar el sentido original de Iglesia. No obstante, el radio de impacto es limitado, pesa más la realidad institucional que los esfuerzos arqueológicos de reinterpretación. ¿Esto significa abandonar "Iglesia" y utilizar otra expresión o sintagma contemporáneo que condiga con la realidad que se predica de ella, por ejemplo, las sociedades en movimiento? En otras palabras, ¿las sociedades en movimiento pueden ser catalogadas como iglesias según el mundo neotestamentario? La respuesta dependerá del sentido neotestamentario que se tenga de Iglesia. Pero no es objetivo de este artículo dar una respuesta de ese tipo. Lo que importa aquí es la interpelación comunitaria de esas sociedades que causan memoria de lo que fue la Iglesia en sus inicios o de lo que fue la Iglesia de los pobres en América Latina.

Sin sacralizar a esas sociedades en movimiento, no se puede negar que ellas muestran una nueva creación social. Dicha nueva creación está vinculada a la teología del bautismo. El hombre se incorpora a Jesucristo, renace en Él. Se convierte en una nueva criatura que le permita entrar en la dinámica histórica para vivir la fe. Cuando se observa el renacer histórico de estos hombres y mujeres en vida comunitaria, se presencia una nueva creación. Indudablemente, no se está hablando a un nivel sacramental sino histórico. El renacer se debe a la lucha cotidiana por otro modo de existencia social. ¿Quién los impulsa a ello? El grito interior por vivir. La vida reclama vida digna. Se trata, pues, del regreso al Dios de la vida.

3 Para más información, véase Boff (1992, pp. 207-217), Sobrino (1981, pp. 99-142), Ellacuría (1984, pp. 158, 170, 206-208). 
El Dios de la vida no es una fórmula teórica, sino un credo histórico que fue recorriendo las venas de América Latina. Dios es conocido y alabado en estas tierras como el Dios que aboga por la vida de los infantes, de los jóvenes, de los ancianos, de los páramos, de las flores, de los bosques, de los ríos, de los mares y de los animales. Cuando hombres y mujeres irrumpen por la defensa de la vida a través de existencias comunitarias arraigadas en un territorio, dibujan el rostro de la divinidad, de la fuerza espiritual que sacude y ensancha las posibilidades de existencia social.

El retorno de lo comunitario como forma política para resistir los embates del mundo del capital y del poder constituye un epicentro epistémico para enfrentar la muerte. Al presenciar tal retorno, es ineludible la confrontación a la fe cristia-

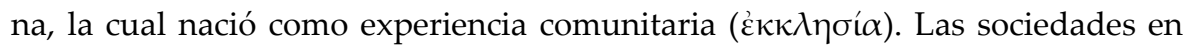
movimiento interpelan a cualquier institución que pregona la vida comunitaria.

\section{Conclusión}

Hacer una lectura del encuentro de Francisco con los movimientos populares, no solo ha significado un recuento del contenido de sus pronunciamientos, sino también ampliar la reflexión a la vida de los movimientos, hasta el punto de reconocer que sería más apropiado nominarlos sociedades en movimiento. Además, se ha visto que la existencia social de esas sociedades toca la columna vertebral del cristianismo: la comunidad.

Ciertamente, Francisco está realizando una aproximación a esas sociedades, pero ello no significa que tenga presente la densidad de su dimensión comunitaria. En general, el magisterio eclesiástico ha tenido una concepción muy abstracta de la sociedad. A este respecto, Marcelo Ciaramella señala lo siguiente:

La sociedad es a menudo presentada como una prolongación del individuo y pareciera que lo que sea asumido a nivel individual se descuenta que se extenderá a la sociedad. No hay en los textos una mirada sociológica o antropológica que permita observar la sociedad como una entidad que es influida por individuos o puede influir sobre ellos, que tiene sus problemáticas, correlación de fuerzas y estructuras propias que sería menester analizar para elaborar respuestas desde la perspectiva cristiana en este caso. Y en esta línea la DSI [Doctrina Social de la Iglesia] carece de un adecuado análisis de la realidad social. (Rauber, 2017, p. 214) 
La acción de Francisco al encontrarse con las sociedades en movimiento puede constituir una ruptura epistemológica a propósito del análisis de realidad social. Se abre una ventana en que la DSI deje de ser un comunicado a los líderes políticos y se convierta en una lectura de la realidad de los oprimidos. En otras palabras, que la palabra eclesial esté hidratada de la sangre de los pueblos que reclaman la liberación.

Después de este análisis, la Iglesia no puede limitarse a la valoración de un mero reconocimiento del pobre en cuanto sujeto, pues con seguridad la tendencia teológica no pasará de una Iglesia constituida que se une a los pobres, pero que no se ve afectada en sus estructuras y en el modo de hacer teología. En cambio, si la brújula epistemológica comprende un diálogo crítico con el modo de existir de los movimientos populares, es probable que entremos en una nueva fase, no solo de la recepción del concilio, sino de la teología latinoamericana. Deconstruir la fe en el Dios de la vida a partir de la acción que crea y transforma la sociedad. Esto va más allá de simples reformismos. Se dirige a plantear en el escenario popular y académico otra comprensión de la historia desde la acción social.

Pues bien, la cultura del encuentro con las sociedades en movimiento se erige como el nuevo areópago para pensar los problemas sociales. A partir de esto, no es difícil avizorar una pastoral de futuro, a saber: transitar de la cultura del encuentro a la cultura del hermanamiento para otro modo de existencia social en que la persona, la comunidad y la naturaleza no colisionen entre sí, sino que favorezca la vida. La Iglesia está llamada a reinventarse, a hacer mestizaje con esos hombres y mujeres de comunidad. José María Arguedas decía: “Y corrí, cuesta abajo, a entroparme [las cursivas son mías] con los comuneros" (1974, p. 46). El hermanamiento es la posibilidad real para construir una Iglesia de todas las sangres.

\section{Referencias}

Angarita, C. (2016). La constitución del ser humano como sujeto: teología de la liberación y pensamiento crítico. Bogotá, Colombia: Pontificia Universidad Javeriana.

Arguedas, J. (1974). Agua y otros cuentos indígenas. Lima, Perú: Milla Batres.

Boff, C. (2007). Teología de la liberación y vuelta al fundamento. Revista Eclesiástica Brasileira, 268, 1001-1027.

Boff, L. (1992). Iglesia, carisma y poder: ensayos de eclesiología militante. Santander, España: Sal Terrae.

Ellacuría, I. (1984). Conversión de la Iglesia al Reino de Dios: para anunciarlo y realizarlo en la historia. Santander, España: Sal Terrae. 
Francisco. (2013). Evangelii gaudium. Madrid, España: Biblioteca de Autores Cristianos.

Francisco. (2016a). Discurso del santo padre Francisco a los participantes en el Encuentro Mundial de Movimientos Populares. Recuperado de https://w2.vatican.va/content/ francesco/es/speeches/2014/october/documents/papa-francesco_20141028_incontro-mondiale-movimenti-popolari.html

Francisco. (2016b). Participación en el II Encuentro Mundial de los Movimientos Populares. Discurso del santo Padre. Recuperado de: https://w2.vatican.va/content/francesco/ es/speeches /2015/july/documents/papa-francesco_20150709_bolivia-movimenti-popolari.html

Gutiérrez, G. (1979). La fuerza histórica de los pobres. Lima, Perú: CEP.

Holloway, J. (2002). Cambiar el mundo sin tomar el poder: el significado de la revolución hoy. Madrid, España: Ediciones de Intervención Cultural.

Kasper, W. (2015). El papa Francisco: revolución de la ternura y el amor. Burgos, España: Sal Terrae.

Rauber, I. (2017). Laudato si': reflexiones ecuménicas y marxistas para una nueva civilización. Bogotá, Colombia: Desde Abajo.

Scannone, J. (2015) El papa Francisco y la teología del pueblo. Selecciones de Teología, 54(213), 39-50.

Sobrino, J. (1981). Resurrección de la verdadera Iglesia: los pobres, lugar teológico de la eclesiología. Santander, España: Sal Terrae.

Stedile, J. (2015). El papa Francisco y los movimientos populares: la importancia de una aproximación histórica. América Latina en Movimiento, 505, 1-2.

Torres, C. (2016). Educación popular y movimientos sociales en América Latina. Buenos Aires, Argentina: Biblos.

XII Asamblea General Ordinaria del Sínodo de los Obispos. (2012). Mensaje al pueblo de Dios. Recuperado de http://www.vatican.va/roman_curia/synod/documents/ rc_synod_doc_20121026_message-synod_sp.html

Zibechi, R. (2000). La mirada horizontal. Quito, Ecuador: Abya-Yala.

Zibechi, R. (2003). Los movimientos sociales latinoamericanos: tendencias y desafíos. OSAL: Observatorio Social de América Latina, 9, 185-188.

Zibechi, R. (2007). Dispersar el poder: los movimientos sociales como poderes antiestatales. Bogotá, Colombia: Desde Abajo.

Zibechi, R. (2017). Movimientos sociales en América Latina: el "mundo otro" en movimiento. Bogotá, Colombia: Desde Abajo. 